\title{
Changing trends of maternal mortality with its causes- ten years retrospective study in a peripheral medical college of West Bengal, India
}

\author{
Anjan Dasgupta ${ }^{1}$, Abirbhab Pal ${ }^{1 *}$, Nikita $^{1}$, Debanjana Dasgupta $^{2}$, Partha Ghosh $^{1}$
}

\author{
${ }^{1}$ Department of Obstetrics and Gynecology, Midnapore Medical College and Hospital, Midnapore, West Bengal, India \\ ${ }^{2}$ Department of Paediatrics, Medical College and Hospital, Kolkata, West Bengal, India
}

Received: 31 January 2021

Accepted: 04 March 2021

\section{*Correspondence:}

Dr. Abirbhab Pal,

E-mail: abirbhabpl@gmail.com

Copyright: (c) the author(s), publisher and licensee Medip Academy. This is an open-access article distributed under the terms of the Creative Commons Attribution Non-Commercial License, which permits unrestricted non-commercial use, distribution, and reproduction in any medium, provided the original work is properly cited.

\begin{abstract}
Background: The estimates of maternal mortality can only be used as a rough indicator of maternal health situation in any given country. High maternal mortality reflects not only in inadequacy of health care services for mothers, but also a low standard of living and socio economic status of the community. Objective was to assess the maternal mortality ratio (MMR), its probable causes and changing trends.

Methods: The present study conducted at Midnapore Medical College (MMC), West Bengal. Data for analysis were collected from medical college record section and maternal death registrar book after having permission from higher authority of the college during the period from January 2009 to 2018 December. Total sample size for this period was 249. Statistical analysis was done through SPSS software.

Results: Ten years data analysis of 249 subjects showed that total live births from January 2009 to December 2018 was $1,39,126$ with MMR $178.97 \%$. Hypertensive disorder of pregnancy $(40.56 \%)$ was the leading direct cause of maternal death followed by hemorrhage $(24.49 \%)$ and septicemia $(10.84 \%)$. Heart disease $(6.42 \%)$ was the major indirect cause of death followed by anemia (3.6\%). Maternal death rate found high among primi gravida $(59.43 \%)$ mothers and within 20 years age group $(46.18 \%)$.

Conclusions: Most maternal deaths are preventable by proper antenatal care, early diagnosis of high risk factors, timely referral to tertiary care centre along with community upliftment especially in rural and tribal based population.
\end{abstract}

Keywords: Hypertensive disorder, Maternal mortality ratio, Primigravida

\section{INTRODUCTION}

Maternal death is defined as "the death of a woman while pregnant or within 42 days of termination of pregnancy irrespective of the duration and site of pregnancy from any cause related to or aggravated by pregnancy or its management but not from accidental or incidental causes". Maternal mortality ratio (MMR), i.e. the number of maternal deaths per 100000 live births, when remains high, not only reflects overall ineffectiveness of health care system in a country, but also gives consideration to poor literacy, weak administration, failed implementations of strategic approaches, inadequate financial investments, technical incapacities and weak transport system. ${ }^{2}$ It is one of the leading causes of death for women of reproductive age in many parts of the world. An estimated 44000 mothers continue to die every year due to causes related to pregnancy, child birth and postpartum period. ${ }^{2}$ A woman is most vulnerable at the postpartum period. About 50-70\% maternal deaths occurs in the postpartum period of which $45 \%$ deaths occur in the first 24 hours delivery and more than two-thirds during first week. ${ }^{3}$ Despite substantial progress on maternal mortality, neither MDG4 nor MDG5 targets were met. Globally, women face a 1 in 180 lifetime risks of dying due to maternal causes which are dominated by hemorrhage, hypertensive disorders, sepsis and abortion. It is really tragic as these deaths are not caused by disease 
but occurred during or after a natural physiological process. India is amongst those countries which have a high maternal mortality ratio though the MMR has reduced from 167 per lakh live births in 2011-13 to 130 per lakh live births in 2014-16. States of Kerala, Maharashtra, Andhra Pradesh, Gujarat and Tamil Nadu have already achieved the goal of a MMR of 100 per lakh live births. ${ }^{4}$ Most maternal deaths and pregnancy complications can be prevented if pregnant mothers have access of good quality antenatal, natal and postnatal care and certain harmful birth practices are avoided. In December 2015, the Millennium Development Goals came to an end of their term and a post-2015 agenda comprising 17 Sustainable Development Goals (SDGs) takes their place up to 2030, targets to reduce the global maternal mortality ratio to less than 70/100000 live births. $^{5}$ This study attempts to study the trends and association of various causes of maternal mortality in last ten years in a peripheral medical college and various others factors responsible for it.

\section{METHODS}

This was a retrospective analysis of patients admitted between January 2009 to December 2018 in the department of Obstetrics and Gynecology of Midnapore Medical College, West Bengal. Patients who died due to complications of pregnancy, labor and puerperium were included. A total of 249 patients who died within 42 days of termination of pregnancy irrespective of duration and site of gestation and deaths resulted from disease present before or developed during pregnancy were also included in the study. During this period of 10 years, 1,39,126 live births was recorded with 249 maternal deaths, i.e. MMR found to be 178.97. The available records were collected from medical college record section and maternal death registrar book after having permission from higher authority of the college. Information regarding demographic and reproductive profile, booked or unbooked, cause of death and time interval from admission to death were collected from the records of labor room registrar. After collecting the data, statistical analysis was generated through MS excel sheet and analysis was done using SPSS 23 software.

\section{RESULTS}

During the study period from January 2009 to December 2018, there were $1,41,396$ deliveries with 1,39,126 live births took place along with 11,581 abortions and 2018 ectopic pregnancies. There was 249 maternal deaths (Figure 1), so MMR in our study was 178.97 i.e. grossly $179 / 100000$ live births. During 2009-2013, there were a total of 69,438 deliveries, 68,428 live births and 110 maternal deaths whereas during 2014-18, there were 71,958 deliveries, 70698 live births and 139 maternal deaths. It was observed that much higher death rates found among unbooked and referred cases $(179,71.89 \%)$ in comparison to booked cases $(70,28.11 \%)$. Out of total 1, 41,396 deliveries, $66.41 \%(93,908)$ had normal vaginal deliveries, $1.04 \%$ (1476) instrumental deliveries (forceps and ventouse) and $32.54 \% \quad(46,012)$ had cesarean sections.

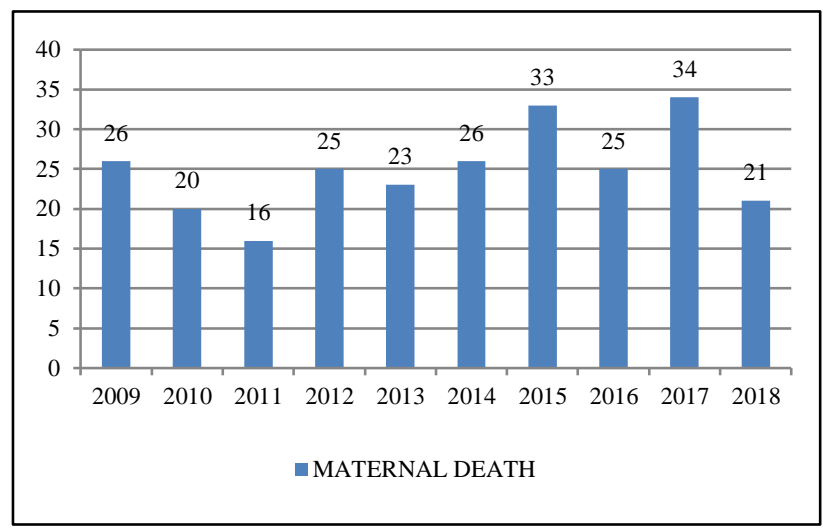

Figure 1: Year wise distributions of maternal deaths.

Figure 1 shows year wise distributions of maternal deaths in our study during the period from 2009-2018 along with its graphical representation. A minimum death recorded in 2011 and maximum in 2017.

Table 1: Shows age and parity wise distributions of maternal deaths.

\begin{tabular}{|llll|}
\hline Age $($ years $)$ & Percentage & Parity & Percentage \\
\hline <20 years & 46.18 & P1 & 59.43 \\
\hline 21-25 years & 35.34 & P2 & 20.88 \\
\hline 26-30 years & 12.85 & P3 & 13.25 \\
\hline 31-35 years & 2.81 & P4 & 13.25 \\
\hline >35 years & 2.81 & P5 & 1.2 \\
\hline - & - & P6 & 0.4 \\
\hline Total & 100 & & 100 \\
\hline
\end{tabular}

Table 2: Admission- death interval in relation to maternal death.

\begin{tabular}{|lll|}
\hline Time interval & $\begin{array}{l}\text { Number of maternal } \\
\text { death }(\mathbf{n = 2 4 9})\end{array}$ & Percentage \\
\hline <6 hours & 62 & 24.90 \\
\hline 6-12 hours & 43 & 17.27 \\
\hline 12-24 hours & 47 & 18.87 \\
\hline $\mathbf{2 4 - 4 8}$ hours & 37 & 14.86 \\
\hline 48-72 hours & 14 & 5.62 \\
\hline $\mathbf{7 2 - 9 6}$ hours & 24 & 9.64 \\
\hline 96-120 hours & 09 & 3.61 \\
\hline 5-15 days & 13 & 5.23 \\
\hline Total & 249 & 100 \\
\hline
\end{tabular}

Table 2 shows details of time interval between admission and maternal death.

After analysing age wise distributions of maternal deaths, much higher death rate identified within 20 years age group, $46.18 \%$ (115) followed next by $35.34 \%$ (88) in 21 - 
24 years age group and combined these two groups responsible for more than $80 \%$ of total maternal deaths. (Table 1). Similarly, parity wise distributions showed primigravida being the major portion $(59.43 \%)$ of maternal deaths (Table 1). After analysing of direct causes of maternal deaths (86.34\%, Table 3), it was found that hypertensive disorder of pregnancy causing maternal death in $40.56 \%$ of cases whereas hemorrhage and septicemia responsible for maternal death in $24.49 \%$ and $10.84 \%$ of cases. These three main causes were responsible for $79.89 \%$ of maternal deaths in this study. Out of total 101 cases of hypertensive disorder in pregnancy, majority had eclampsia (64), 35 were severe preeclampsia and 2 were suffering from hypertensive encephalopathy. Hemorrhage (24.49\%, PPH-49, APH-03, ruptured ectopic- 07, abortion- 02) was the second and septicemia (10.84\%, puerperal sepsis- 11, endotoxic shock- 02, infection- 12, septicemia with DIC- 02) was the third common cause maternal deaths. Embolism (6.42\%, pulmonary embolism -14, amniotic fluid embolism- 2) and post cesarian complications (4.01\%) were the other direct causes of maternal deaths. Among the indirect causes of deaths $(13.66 \%)$, heart disease $(6.42 \%)$ and severe anemia $(3.6 \%)$ were the two major causes of maternal deaths in our study. Other indirect causes include death due to jaundice with hepatic encephalopathy, CNS disorder, anaphylactic reaction and acute renal failure.

Table 3: Causes of maternal death.

\begin{tabular}{|c|c|c|c|}
\hline Direct causes $(\mathrm{n}=\mathbf{2 1 5}) \mathbf{8 6 . 3 4 \%}$ & & Indirect causes $(n=34) 13.66 \%$ & \\
\hline 1. Hypertensive disorder & \multirow{6}{*}{$101(40.56 \%)$} & 1. Heart disease & \multirow{6}{*}{$16(6.42 \%)$} \\
\hline \multirow{2}{*}{ Severe preeclampsia $=35$} & & Vulvular disease $=06$ & \\
\hline & & \multirow{2}{*}{$\begin{array}{l}\text { Other heart disease (cardiomyopathy and } \\
\text { others) }=06\end{array}$} & \\
\hline \multirow{2}{*}{ Eclampsia=64 } & & & \\
\hline & & Sudden cardiac arrest $=03$ & \\
\hline Hypertensive encephalopathy $=02$ & & Acute myocardial infarction $=01$ & \\
\hline 2. Haemorrhage & \multirow{5}{*}{$61(28.37 \%)$} & 2. Severe anaemia & $9(3.6 \%)$ \\
\hline $\mathrm{PPH}=49$ & & \multirow{4}{*}{$\begin{array}{l}\text { 3. Jaundice with hepatic } \\
\text { encephalopathy }\end{array}$} & \multirow{4}{*}{$4(1.60 \%)$} \\
\hline $\mathrm{APH}=03$ & & & \\
\hline Rupture ectopic $=07$ & & & \\
\hline Abortion $=02$ & & & \\
\hline 3. Septicemia & \multirow{5}{*}{$27(12.55 \%)$} & 4. CNS disorder & \multirow{5}{*}{$3(1.20 \%)$} \\
\hline Puerperal sepsis $=11$ & & & \\
\hline Entotoxic shock=02 & & Meningo-encephalitis $=02$ & \\
\hline Infection $=12$ & & & \\
\hline Septicemia with $\mathrm{DIC}=02$ & & Seizure disorder $=01$ & \\
\hline 4. Embolism & \multirow{3}{*}{$16(7.44 \%)$} & \multirow{3}{*}{$\begin{array}{l}\text { 5. Anaphylactic reaction following } \\
\text { transfusion }\end{array}$} & \multirow{3}{*}{$1(0.40 \%)$} \\
\hline Pulmonary embolism=14 & & & \\
\hline Amniotic fluid embolism $=02$ & & & \\
\hline 5. LUCS/post LUCS complications & \multirow{5}{*}{$10(4.65 \%)$} & \multirow{5}{*}{ 6. Acute renal failure } & \multirow{5}{*}{$1(0.40 \%)$} \\
\hline Ruptured uterus $=06$ & & & \\
\hline Broad ligament hematoma $=02$ & & & \\
\hline Rectus sheath hematoma $=01$ & & & \\
\hline Re laparotomy=01 & & & \\
\hline
\end{tabular}

\section{DISCUSSION}

Maternal mortality is a global health problem. Maternal death has severe impact not only on family and community, but also on the nation and that's why reduction of MMR is the primary objective of National Health Mission. The MMR in India has declined to 113 in 2016-18 from 122 in 2015-17 and 130 in 2014-16 according to the special bulletin released by the Office of the Registrar General's Sample Registration System (SRS). ${ }^{6}$ In our study, higher rate of maternal deaths (MMR-179) was documented. The probable factors responsible includes: patients often arrived late from remote and rural geographic areas, less access of good quality transport/referral system, slightly lower awareness of antenatal care schedules, relatively younger age of marriage and first pregnancy and less than average nutritional status. In our study, highest number of mothers died among the age group $<20$ years to 25 years $(81.52 \%$, Table 1), primigravida $(59.43 \%$, Table 1) and unbooked/referred cases $(71.89 \%)$. In the current study, hypertensive disorders of pregnancy was the leading cause $(40.56 \%$, Table 3$)$ maternal death followed by hemorrhage $(24.49 \%)$ and septicemia $(10.84 \%)$. Other studies done by Purandre et al and Priya et al few years back, hemorrhage was the leading cause of maternal 
death in $35.05 \%$ and $70.83 \%$ cases respectively. ${ }^{7,8}$ Here, our study shows the major causes of maternal deaths by different authors in their studies. ${ }^{9-11}$ Eclampsia was the single most common cause of maternal death in our study $(40.56 \%)$, which is similar to studies done by Mootha et al, Sundari et al and Milan Taye et al., ${ }^{9,13}$ Higher mortality in eclampsia or severe preeclampsia was may be due to lesser health awareness, late diagnosis of the condition and reach tertiary centre at severe condition. Rao et al and Sarkar et al reported similar results in their studies. ${ }^{14,15}$ Hemorrhage and sepsis are the two other important causes of maternal death in the list.

Table 4: Study comparison with other authors in India.

\begin{tabular}{|c|c|c|c|c|c|c|c|}
\hline $\begin{array}{l}\text { Name of the } \\
\text { author }\end{array}$ & $\begin{array}{l}\text { Vidhyadhar } \\
\text { et } \mathbf{a l}^{10}\end{array}$ & $\begin{array}{l}\text { Jadhav et } \\
\text { al }^{16}\end{array}$ & Patil et al $^{17}$ & Zaman et al ${ }^{18}$ & $\begin{array}{l}\text { Mootha et } \\
\mathrm{al}^{9}\end{array}$ & Taye et $\mathbf{a l}^{13}$ & $\begin{array}{l}\text { Our } \\
\text { study }\end{array}$ \\
\hline Year & $2006-10$ & $2007-12$ & 2009-11 & $2012-13$ & $2006-14$ & $2012-15$ & $2009-18$ \\
\hline Total live birth & 12,544 & 39,905 & 13,188 & 10,291 & 85,404 & 33,833 & $1,39,126$ \\
\hline Maternal deaths & 38 & 158 & 63 & 73 & 183 & 279 & 249 \\
\hline MMR & 302.9 & 395 & 477 & 709.35 & 341.90 & 824.64 & 178.97 \\
\hline Age group in years & $\begin{array}{l}19-29 \text { years- } \\
68.42 \%\end{array}$ & $\begin{array}{l}20-29 \\
\text { years- } \\
74.67 \%\end{array}$ & $\begin{array}{l}20-29 \\
\text { years- } \\
74.6 \%\end{array}$ & $\begin{array}{l}18-29 \text { years- } \\
75.32 \%\end{array}$ & $\begin{array}{l}20-29 \text { years- } \\
80.7 \%\end{array}$ & $\begin{array}{l}20-30 \text { years } \\
80.29 \%\end{array}$ & $\begin{array}{l}17-25 \text { years } \\
81.52 \%\end{array}$ \\
\hline$\%$ of primi gravida & $42.10 \%$ & $49.36 \%$ & $46.03 \%$ & $43.835 \%$ & $45.2 \%$ & $52.32 \%$ & $59.43 \%$ \\
\hline Booked /unbooked & $\begin{array}{l}28.94 \% / \\
71.06 \%\end{array}$ & $\begin{array}{l}78.48 \% / \\
21.51 \%\end{array}$ & $\begin{array}{l}74.60 \% / \\
25.40 \%\end{array}$ & $\begin{array}{l}8.62 \% / \\
91.38 \% \\
\end{array}$ & $\begin{array}{l}66.8 \% 1 \\
33.2 \%\end{array}$ & $\begin{array}{l}17.20 \% / \\
82.80 \%\end{array}$ & $\begin{array}{l}28.11 \% / \\
71.89 \%\end{array}$ \\
\hline $\begin{array}{l}\text { Adm-death } \\
\text { interval }\end{array}$ & - & 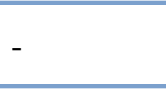 & 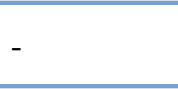 & - & - & $\begin{array}{l}<4 \text { hours- } \\
21.52 \%\end{array}$ & $\begin{array}{l}<6 \text { hours- } \\
24.90 \%\end{array}$ \\
\hline Direct cause & $50 \%$ & $73.2 \%$ & $52.35 \%$ & $69.84 \%$ & $62.7 \%$ & $70.61 \%$ & $86.34 \%$ \\
\hline Indirect cause & $50 \%$ & $26.8 \%$ & $47.65 \%$ & $30.16 \%$ & $37.3 \%$ & $29.39 \%$ & $13.66 \%$ \\
\hline
\end{tabular}

Table 4 shows few parameters of MMR studies by different authors which includes study span in years, total number live births and maternal deaths, MMR, most vulnerable age group and parity, booked or un-booked, admission-death interval during first few hours and percentage of direct and indirect causes of maternal deaths. It has shown in every study that primigravida and younger age group are at the greater life risk for pregnancy and child birth. Among 18-29 years age group, Vidhyadhar et al showed 68.42, Jadhav et al showed $74.67 \%$, Patil et al showed $74.60 \%$, Zaman et al showed $75.32 \%$ and Mootha et al showed $80.7 \%$ maternal deaths. ${ }^{9,10,16-18}$ In comparison to above mentioned studies, much higher results had been found in our study, $81.52 \%$ maternal death found in 17-25 years age group (Table 1). Much higher rate of maternal death has also found among primigravida group (Table 1).

Jadhav et al reported $49.36 \%$, Patil et al reported $46.03 \%$ and Mootha et al reported $45.2 \%$ maternal deaths among primigravida whereas in our study, it was $59.43 \% .^{9,17}$ Higher rate of unbooked patients found in different studies like Vidhyadhar et al $(71.06 \%)$, Zaman et al $(91.38 \%)$ and Taye $(82.80 \%)$, in our study it was $(71.89 \%))^{10,13,18}$ Earlier admission and initiation of definitive treatment is necessary to reduce maternal deaths as maximum death occurs within first 24 hours of admission. Taye et al showed $21.52 \%$ maternal death within 4 hours; similarly in our study, it was $24.90 \%$ within 6 hours (Table 2). Direct causes responsible for $50 \%$ to $73.2 \%$ maternal death in different studies, whereas in our study it was $86.34 \%$ (Table 3). Pulmonary embolism responsible for $5.62 \%$ maternal deaths in our study, where as it was $1.43 \%$ in study done by Taye et al. It is interesting to note that preeclampsia-eclampsia associated with $50 \%$ cases of pulmonary embolism.

Due to much liberalization of cesarian section in recent years, there is increasing maternal complications which leads to increasing maternal morbidity and mortality. In our study, $4.01 \%$ maternal deaths had recognized due to LUCS complications (Table 3). Though anemia is the major indirect cause of maternal deaths in studies done by Taye et al $(24.73 \%)$, Doddamani et al and Kashyap et al $(11.8 \%)$, heart disease was responsible for $6.42 \%$ and anemia contributes $3.6 \%$ of maternal deaths in current study. ${ }^{11,13,19}$

\section{CONCLUSION}

Most of the maternal deaths are preventable. This study was an attempt to provide information on different factors which had contributed to maternal deaths in a tertiary care hospital and timely interventions could prevent such type of mishaps in a majority. As obstetrical causes account for a considerable portion of those deaths, can only be prevented if antenatal mothers are motivated for regular antenatal check-up, diagnosed earlier the high risk factors and could avail quick transport system to tertiary care centre whenever necessary. Last but not the least, upliftment of the social and environmental factors like 
poverty, female literacy, prejudices and low level of nutrition are necessary to decline MMR. .

Funding: No funding sources

Conflict of interest: None declared

Ethical approval: The study was approved by the Institutional Ethics Committee

\section{REFERENCES}

1. World Health Organization. Regional Office for South-East Asia. (2005). Regional Health Forum, Vol. 9, No. 1. WHO Regional Office for South-East Asia. Available from: https://apps.who.int/iris/handle/10665/205800.

Accessed on 2 December 2019.

2. Demography and Family Planning; Delivering the MCH Services. In: Park K, ed. Text book of Preventive and Social Medicine. 25th edn. M/s Banarsidas Bhanot Publishers; 2019:614-615.

3. WHO, UNICEF, World Bank. Trends in Maternal Mortality; 1990-2008, Estimates developed by WHO, UNICEF, UNFPA and the World Bank. 2010.

4. Government of India. Special Bulletin on Maternal Mortality in India 2014-16, SRS, Office of Registrar General of India. 2018. Available from: https://censusindia.gov.in/vital_statistics/SRS_Bullet ins/MMR\%20Bulletin-2014-16.pdf. Accessed on 2 December 2019.

5. WHO, UNICEF, UNFPA, World Bank Group and the United Nations Population Division. Trends in maternal mortality: 1990 to 2015. Estimates by WHO, UNICEF, UNFPA, World Bank Group and the United Nations Population Division; 2015.

6. Maternal Mortality Ratio (MMR) in India, July18, 2020. NEO IAS Current Affairs Plus. Available from: https://neoiascap.com/2020/07/18/maternalmortality-ratio-mmr-in-india/social-sector/health/. Accessed on 2 December 2019.

7. Purandre N, Chandock A, Upadhya S, Sanjanwala SM. Maternal mortality at a referral centre: a five year study. J Obstet Gynecol India. 2007;57:248-50.

8. Priya N, Verma A, Verma S. Maternal mortality: ten years retrospective study. J Med Educ Res. 2010;12:134-6.

9. Mootha S, Bathula U. Evaluation of maternal mortality rate (MMR) at a high volume tertiary centre: what are we missing? A study spanning 85404 live births over 9 years. Int J Sci Res. 2013;4(1):302-4.

10. Vidhyadhar B, Purushottam A, Giri B, Garg RC. Maternal mortality at a tertiary care teaching hospital of rural India, a retrospective study. Int J Biol Med Res. 2011;2(4):1043-6.

11. Doddamani U, Rampure N, Kaveri, Pooja. A study of maternal mortality in a tertiary care hospital. Int $\mathbf{J}$ of Reprod Contracept Obstet Gynecol. 2018;7(6):2446-8.

12. Sundari KPM, Jayanti RD, Ramaswamy B. Trends in a tertiary care hospital. Int $\mathbf{J}$ of Reprod Contracept Obstet Gynecol. 2016;5(11):3659-62.

13. Taye M, Alam A, Rakshita. Retrospective evaluation of causes and social correlates of maternal deaths at Assam Medical College and Hospital, Dibrugarh, Assam, India. J Evol Med Dent Sci. 2018;5(05):2759.

14. Rao PVR, Jayanthi P. Maternal mortality: a retrospective study in a tertiary centre. $\mathrm{J}$ Evol Med Dent Sci. 2015;4(14): 2247-54 .

15. Sarkar M, Basak SK, Das S, Roy D, Mandal J. Maternal mortality associated with eclampsia in an Indian medical college: a four year retrospective study. J Med Sci. 2013;4(10):394-8.

16. Jadhav CA, Prabhakar G, Shinde MA, Tirankar VR. Maternal mortality: five year experience in tertiary care centre. Indian J Basic Appl Med Res. 2013;7(2):702-9

17. Patil VN, Shinde MA, Surve M, Sonone SG. Maternal Mortality A Challenge? JKIMSU. 2013;2(1):58-61.

18. Zaman S, Begum AA. Maternal mortality at a rural medical college of Assam: a retrospective study. J Obstet Gynecol Barpeta. 2014;1(1):46-51.

19. Kashyap V, Kumar M, Kumar A, Kanayamkandy J. Trends and causes of maternal mortality in a tertiary care hospital in Jharkhand, India: a five years retrospective study. Int $\mathbf{J}$ Community Med Public Health. 2016;3(11):3030-32.

Cite this article as: Dasgupta A, Pal A, Nikita, Dasgupta D, Ghosh P. Changing trends of maternal mortality with its causes- ten years retrospective study in a peripheral medical college of West Bengal, India. Int J Reprod Contracept Obstet Gynecol 2021;10:1649-53. 